\title{
Designing a model for explanation of the internet banking acceptance rate
}

\author{
Ebrahim Chirani, Mohammad Taleghani* and Yalda Rahmati \\ Department of Management, Rasht branch, Islamic Azad University, Rasht, Iran. \\ Accepted 25 July, 2011
}

\begin{abstract}
The present article tries to utilize structural equations model to explain internet banking acceptance rate. So accordingly, three factors including innovation characteristics of electronic banking system, individual characteristics of bank customers and market facilitating conditions have been used based on different theories proposed. Measurement of the variables by the use of questionnaires based on the comments of internet customers of Guilan province banks and the analysis of those comments through causal model indicated that the characteristics of internet banking system and individual characteristics of customers affect directly on internet banking acceptance rate.
\end{abstract}

Key words: Internet banking, individual characteristics, innovation, structural equations model.

\section{INTRODUCTION}

The adoption of innovations is treated as a vital and significant issue not only in emerging and recently developed economic systems but also in all the developed systems, and in world economy in general. As a result, economic growth is increasingly dependent on world economy capabilities to present innovation. In general, innovation is defined as the new applications of invention, exploration, existing knowledge, or new one. According to this definition, internet banking can also be considered as an innovation that alters the consumption patterns of those who have accepted it (Eriksson et al., 2008). In recent years, internet has fundamentally changed the methods of daily activities of bank customers, and banks have not only utilized it as a new way of increasing customer's satisfaction but also used it as a strategic method to reduce expenses and increase benefits at same time (Atay, 2008).

The term 'internet banking' is referred to using internet as a channel for presenting and delivering banking services consisting of traditional services like opening an account, money transfer, and new services such as

${ }^{\star}$ Corresponding author. E-mail: taleghani@iaurasht.ac.ir

Abbreviations: ATM, Automated teller machine; ISPs, internet service providers. online and electronic payments. Internet banking is in fact defined as banking transaction through internet (Corrocher, 2006). In other words, internet banking can be defined as carrying out all banking operations through bank's website.

Iran is known to be a young country in electronic commerce and electronic banking and needs to be promoted in this area so that it can act as a prerequisite for development for Iran to achieve its financial system objectives in twenty-year panorama. Gradual expansion of access to internet and owning personal computers by people and companies, on the other hand, have displayed potential need in receiving electronic banking services through internet. Although, some methods of providing electronic banking services such as automated teller machine (ATM) machines and debit cards have been used in Iran's banking system for many years, banking structure of this country has been founded on issuing paper documents, and electronic systems have not gained considerable stand in country's banking system. Computers and ATM machines are the only signs of electronic banking. One of the goals of electronic banking is the customers not going to banks branches. In Iran, however, nothing is possible without going to banks. Despite the fact that the country's banking network is active over one year in providing internet banking services to customers, there are few users for it. Based on the statistics issued by technology department of banks in 2008 , out of 
50 million banks card issued in Iran, only 16.5 millions are active in buying through internet (www.ilcell.ir). It is quite clear that providing internet banking system is not accept by customers, providing these services will get defeated. Despite the initial and late acceptance of internet banking in Iran, it seems banks are nowadays aware of the opportunities available due to the use of internet. In fact, they are moving fast toward modern internet banking and providing high rank services to their customers. Since utilization of most electronic methods in banking is regarded as innovation, understanding the characteristics that lead to the acceptance of this innovation helps the country's banking system utilize its marketing strategies for promotion of performance (Atey, 2008). Surveys and studies indicate that three groups of variables including innovation characteristics, individual characteristics and market facilitating condition are the most influential factors on the internet banking acceptance rate. Thus, using a causal model, the present article tries to explain internet banking acceptance rate.

\section{LITERATURE REVIEW}

Literature related to marketing tells that different researchers have investigated the acceptance of internet banking. It can be said that in order to explain the customer's intention of modifying exchange behavior and of deciding to accept internet banking, the marketing and information systems researchers generally make use of technology acceptance model. All these surveys, nevertheless, are of the same opinion that technology acceptance model cannot deservedly explain the customers' decision-making process of accepting internet banking as it is to do. The reason is that the use of technology acceptance model does focus merely on the technologic aspects of internet banking acceptance, and other factors (social and psychological) that have been proven to have meaningful impact on decision to accept or real acceptance are ignored in this model. On the other hand, many researches of this kind that have used technology acceptance model to survey internet banking acceptance, have not gained much success. Chan and Lu (2004), for example, in a survey of Hong Kong banks found that subjective norms and computer self-efficacy have a meaningful impact on the internet banking acceptance while the perceived ease of use has only an indirect effect on the intention of internet banking acceptance by the perceived usefulness. Suh and Han (2002), Chau and Lai (2004) and Eriksson et al. (2005) have reached the same results in their studies. The only research that supports the findings of technology acceptance model is the one done recently by Mckechnie et al. (2007). Even in this case, however, the authors believe that some parameters and other additional factors are required to have a sound understanding of influential factors on the customers' decision of accepting internet banking. It should be mentioned that though considering parameters and additional factors might increase the explanatory power of the model; there is no warrant of this theoretical contribution unless researcher has sufficiently substantiated the relationship and the effects of variables and combined components with adequate reasons and proofs.

Regarding the points mentioned above, the present article suggests a new framework for determining internet banking acceptance. Therefore, three groups of independent variables such as innovation characteristics, market facilitating conditions, and individual characteristics are considered for this issue.

\section{Innovation characteristics}

Innovation characteristics include those innovative features that lead to the sooner, later acceptance or refusal of it by individuals. The use of innovation is in fact attributed to its features; that is, the decision to accept innovation depends on the perception of innovation characteristics by the members of social system (Rogers and Shoemaker, 1971). Innovation characteristics presented in model are taken from perceived characteristics of innovation theory since it was shown in previous studies that the perceived characteristics of innovation theory creates a theoretical and comprehensive framework for better description of more complicated phenomena of innovation acceptance like internet banking. On the other hand, a research was done to investigate the drivers for deciding to accept internet banking. The goal was to compare two models, technology acceptance model and innovation diffusion theory along with perceived characteristics of innovation theory that are frequently accepted and used in the literature of innovation acceptance. The findings displayed was compared to the two models mentioned above, the perceived characteristics of innovation theory act better in predicting the customers' acceptance of internet banking, and adding more individual characteristics increases the prediction ability of the model. According to this theory, the perceived characteristics of innovation include relative advantage, compatibility, ease of use, trial ability, image, voluntariness, visibility and result demonstrability. For this reason, Moore and Benbasat have merged the mutual relationships among these derivers and technology acceptance in a unified and comprehensive framework that consist of eight parameters that are described as follows (Gounaris and Koritos, 2008).

Relative advantage: The extents to which innovation is perceived to be better than what supersedes and one believes that it enhance his/her job performance.

Ease of use (complexity): the extent to which person believes that learning how to use and using innovation do 
not require much effort.

Compatibility: the extent to which one believes that innovation is consistent with existing values, past experiences and needs

Trial ability: the extent to which the innovation can be experimented with on a limited basis and before it is really accepted

Result demonstrability: the extent to which users believe that explaining the result of innovation use to others is easy

Image: the extent to which the users perceived that the use of technology-based innovation results as adding prestige to their social icon

Voluntariness: the extent to which the users believe that the use of technology-based innovation is compulsory/ optional

Visibility: the extent to which the benefits or attributes of the innovation are visible to prospective adopter.

\section{Market facilitating conditions}

Facilitating conditions refers to availability of physical (money, time) and technological resources for acceptance (Hernandez and Mazzon, 2007). In fact, facilitating conditions involve external control (market) over innovation acceptance. If there are fewer resources available, behavioral intention and the use of technology get probably down. Naturally, lack of facilitating resources creates some obstacles for the use, and the presence of facilitating conditions encourages the number of uses (Taylor and Todd, 1995). To do so, from the decomposed theory of planned behavior and the perceived behavioral control construct, the factor of facilitating conditions was taken into the model. Based on the study of Tan and Teo, facilitating conditions can be decomposed to two variables, namely availability of technologic support and availability of government support (Hernandez and Mazzon, 2007).

Accessibility of government support: The term refers to the degree which potential adopters believe they have government support in acceptance and use of innovation.

Accessibility of technologic support: the term refers to the degree which potential adopters believe they have technologic support in acceptance and use innovation.

\section{Individual characteristics}

One of the significant factors that have gained considerable attention in the literature of innovation acceptance rate is individual characteristics. That consists of personality, demographic and situational variables. Among Individual characteristics, computer self-efficacy, and knowledge of and accessibility to computer were selected as influential variables of individuals on internet banking acceptance. The demographic variables (age, sex, income...) were crossed out due to plenty of surveys in these fields and prevention of making the model complicated.

Knowledge: Knowledge is defined as information, expertise and skills acquired by one due to his/her education, experiences, and self-search. In other words, knowledge can be the perception of unanimous details which have less value by themselves

Computer availability: this term indicates the possibility of access to computer and internet at homes, work place, university or school and so on.

Computer self-efficacy: this concept is related to the understanding of ability to use technology (Hernandez and Mazzon, 2007). In other words, self-efficacy is said to be a personal judgment about his/her ability to have desirable and satisfactory behavior and the degree of achieving the goal. Individuals with stronger self-efficacy will most probably endeavor to achieve their desired goals. Computer self-efficacy refers to the person's selfconfidence in the ability to do all tasks in applied domains of computer (Al-somali et al., 2008).

Regarding the general points earlier mentioned, the design model is shown in Figure 1 based on experimental surveys. The following are hypothesis in the framework of structural equation model.

i. Individual characteristics have direct effect on internet banking acceptance

ii. Innovation characteristics have direct effect on internet banking acceptance

iii. Innovation characteristics have direct effect on individual characteristics

iv. Market facilitating conditions have direct effect on internet banking acceptance

v. Market facilitating conditions have direct effect on individual characteristics

vi Market facilitating conditions have direct effect on innovation characteristics

vii. Innovation characteristics have indirect effect on internet banking acceptance

viii. Market facilitating conditions have indirect effect on internet banking acceptance

\section{METHODOLOGY}

The content of this article is based on a research that is descriptiveanalytical in nature. To collect data, a survey study was done by the use of questionnaire. Various articles, researches and books were 


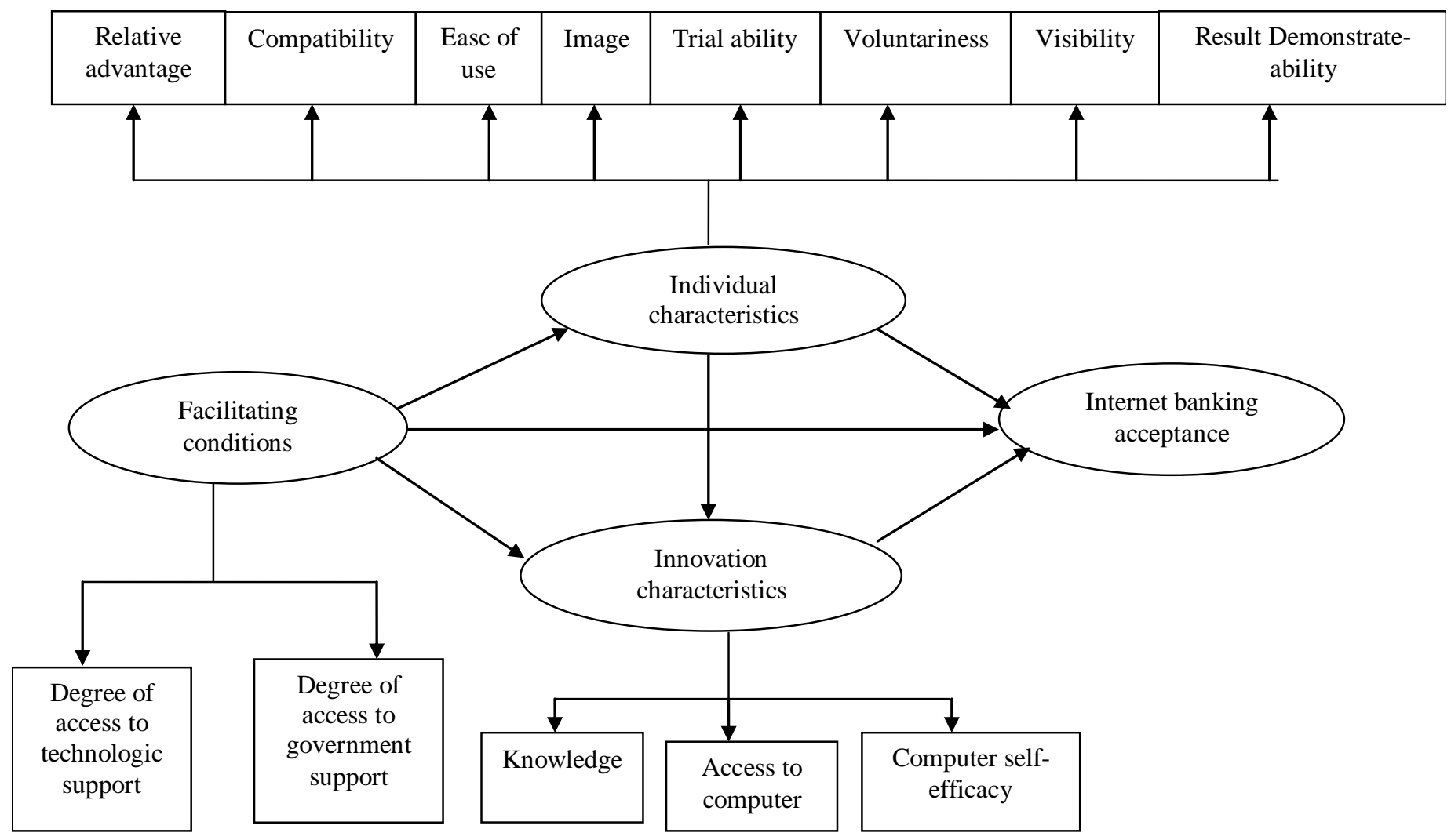

Figure 1. Causal model of survey of Internet banking acceptance.

primarily investigated to design the questionnaire. Then, measurement component were derived to each variable in question. The questionnaire included 45 close questions based on Likert Scale of 5 multiple-choice items. The validity of questionnaire was supported by some of the university teachers, and 20 of informed individuals in banking affaires. Cornbach's alpha coefficient test was used to determine the reliability of the research. The coefficient reached for innovation characteristics, market facilitating conditions, individual characteristics and the internet banking acceptance rate which was $0.85,0.82,0.74$ and 0.80 respectively. This indicates that the questionnaire has the required reliability.

The population in this research includes internet customers of private and governmental banks of Guilan province that were randomly chosen from the banks database. Regarding the very few users of internet banking in Guilan province, only 146 out of 300 questionnaires were filled and then used as samples of research. To describe the data and information gathered and to test the hypotheses, the indicators of descriptive statistics and the structural equation model in terms of causal relations were respectively used. In this research, Lisrel 8.5 software has been used to carry out the structural equation model.

\section{DATA ANALYSIS AND RESULT}

In this part, the results related to the survey of structural equations model and the hypotheses made for the variables are investigated. For this purpose, firstly, the initial model is presented on the basis of a meaningful coefficient test. Hypothesis testing is then described, and the ultimate model is finally proposed. The results of statistical analysis of the research model and the result of hypothesis testing are shown in Figure 2 and Table 1 respectively.

In. $\mathrm{C}=$ Innovation Characteristics

Me. $\mathrm{C} .=$ Market Facilitating Conditions

Pe. C. $=$ Personal Characteristics

$\mathrm{IB}=$ Internet Banking

chi - square $=173.32, d f=113, p-$ value $=0.00023, R M S E A=0.061$

$\frac{\chi^{2}}{d f}=\frac{173.32}{113}=1.53, C F I=0.92, G F I=0.88, A G F I=0.83, I F I=0.92$

The study of the model coefficient of determination indicates that $63 \%$ of changes in the internet banking acceptance rate can be explained by the variables proposed in this model. The determination coefficient of $63 \%$ is quite acceptable in humanism; that is, the research model mainly covers the key variables that affect the internet banking acceptance rate. After describing the fitting of model, hypotheses testing are made.

Considering the coefficients reached, among the components of measuring innovation characteristics, 'voluntariness' component was not statistically meaningful, and was left out. Similarly, regarding the hypotheses 


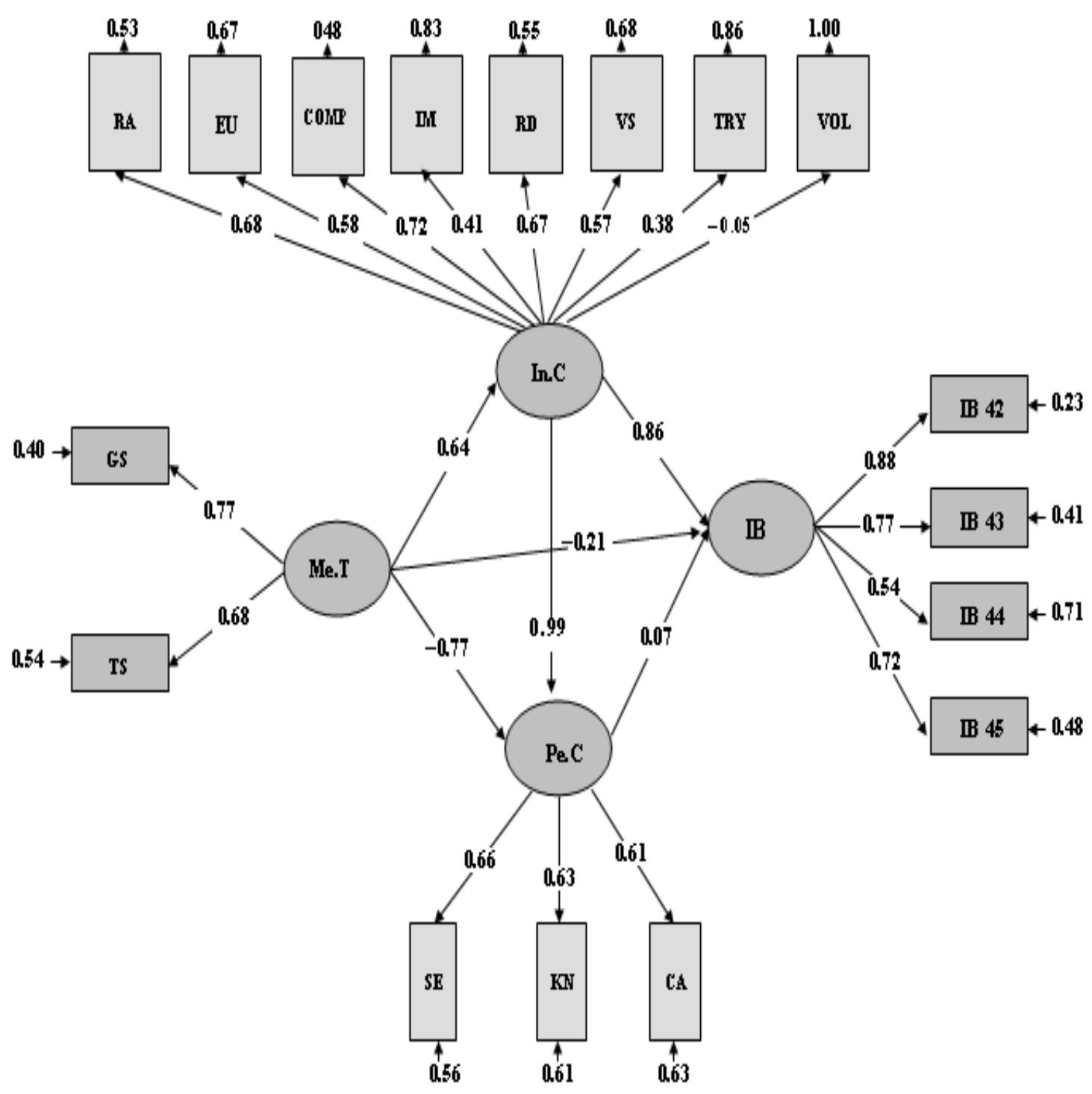

Figure 2. Tested model (standard estimate).

testing, there was no meaningfully structural relationship between market facilitating conditions and internet banking acceptance and it was also left out. By excluding this direction, the structural relationship between individual characteristics and internet banking acceptance rate was found to be meaningful, and it was kept in the model. By omitting the relationships not statistically meaningful in the research model, the final model shown in Figure 3 was achieved.

$$
\begin{aligned}
& \text { chi }- \text { Square }=158.72, d f=99, p-\text { value }=0.00013, R M S E A=0.064 \\
& \frac{\chi^{2}}{d f}=\frac{158.72}{99}=1.60, C F I=0.92, G F I=0.88, A G F I=0.83, I F I=0.92
\end{aligned}
$$

The results reached from the survey of final structural equations in the model indicate that internet banking acceptance rate is directly affected by innovation characteristics and individual characteristics. And, market facilitating conditions have indirect effect on it by means of these two factors. The study of these factors shows that innovation characteristics have the most effect on internet banking acceptance rate. This means that by considering individual characteristics and attending to some aspects of innovation characteristics that need to be supported based on the views of Guilan internet banking customers, internet banking acceptance rate can be increased. It should be mentioned that, in this survey, the direct effect of market facilitating conditions on internet banking acceptance rate was not meaningful. Another point to be mentioned is that there was a negative relationship between market facilitating conditions and individual characteristics affecting internet banking acceptance rate. This relation indicates a perceptualbehavioral pattern in the population in this research that 
Table 1. Structural model result.

\begin{tabular}{|c|c|c|c|}
\hline Hypothesis & Standard estimate & $\mathrm{t}$ value & Test result \\
\hline $\begin{array}{l}\mathrm{H}_{1} \text { : Individual characteristics have direct effect on internet } \\
\text { banking acceptance }\end{array}$ & 0.07 & 0.33 & Rejected \\
\hline $\begin{array}{l}\mathrm{H}_{2} \text { : Innovation characteristics have direct effect on internet } \\
\text { banking acceptance }\end{array}$ & 0.86 & 2.79 & Confirmed \\
\hline $\begin{array}{l}\mathrm{H}_{3}: \text { Innovation characteristics have direct effect on } \\
\text { individual characteristics }\end{array}$ & 0.99 & 4.23 & Confirmed \\
\hline $\begin{array}{l}\mathrm{H}_{4} \text { : Market facilitating conditions have direct effect on } \\
\text { internet banking acceptance }\end{array}$ & -0.21 & -0.83 & Rejected \\
\hline $\begin{array}{l}\mathrm{H}_{5} \text { : Market facilitating conditions have direct effect on } \\
\text { individual characteristics }\end{array}$ & -0.77 & -3.64 & Confirmed \\
\hline $\begin{array}{l}\mathrm{H}_{6}: \text { Market facilitating conditions have direct effect on } \\
\text { innovation characteristics }\end{array}$ & 0.064 & 5.54 & Confirmed \\
\hline $\begin{array}{l}\mathrm{H}_{7} \text { : Innovation characteristics have indirect (the direction of } \\
\text { market facilitating conditions, innovation characteristics, } \\
\text { internet banking acceptance) effect on internet banking } \\
\text { acceptance }\end{array}$ & 0.07 & 1.39 & Rejected \\
\hline $\begin{array}{l}\mathrm{H}_{8} \text { : Market facilitating conditions have indirect (the direction } \\
\text { of market facilitating conditions, innovation characteristics, } \\
\text { individual characteristic, internet banking acceptance) } \\
\text { effect on internet banking acceptance }\end{array}$ & 0.04 & 7.73 & Confirmed \\
\hline
\end{tabular}

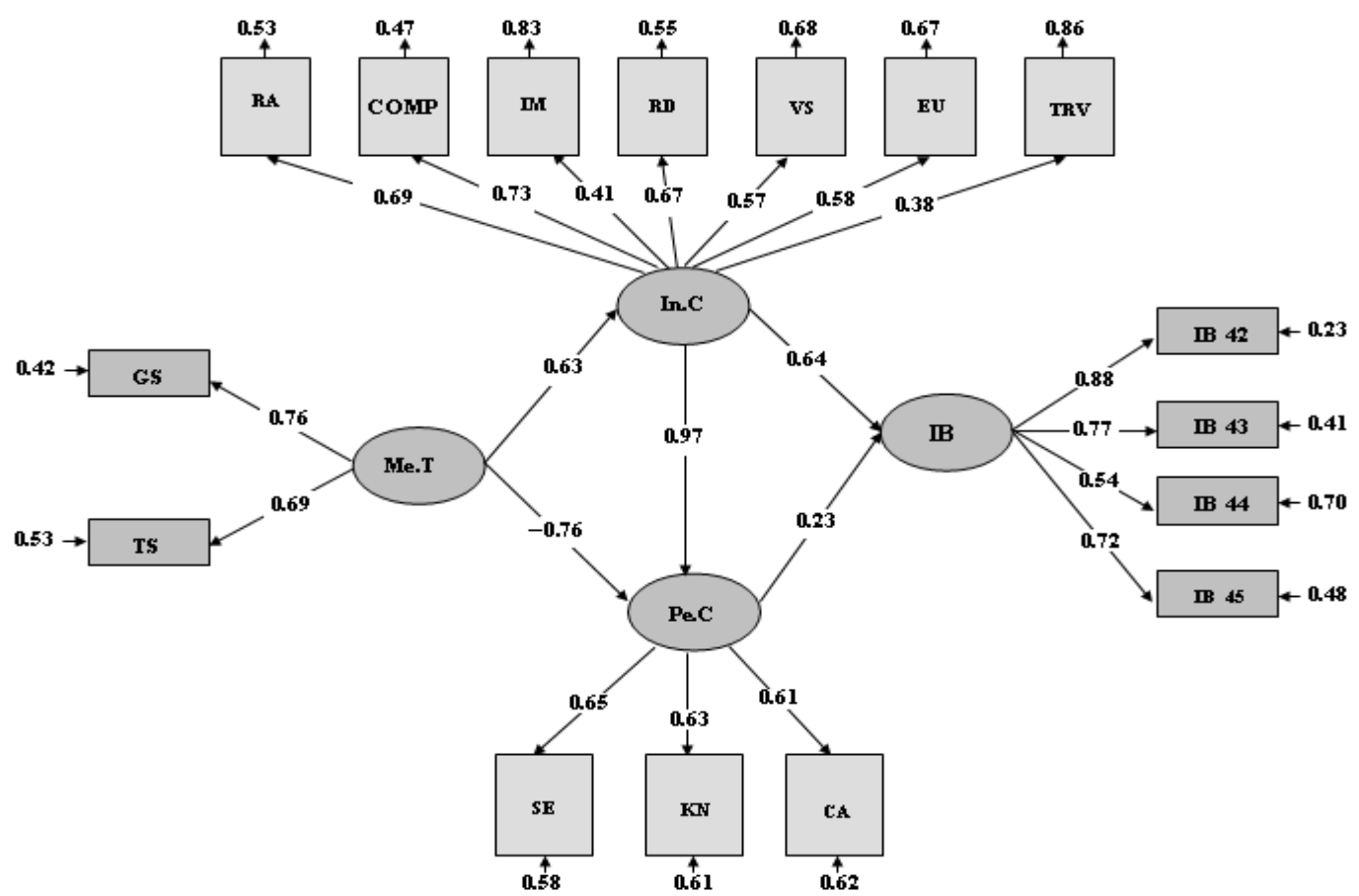

Figure 3. The final model of research (standard estimate). 
can reduce the effectiveness of the government planning.

\section{CONCLUSIONS AND IMPLICATIONS FOR FUTURE DEVELOPMENT}

The growing use of internet has encouraged the companies to advertise and sell their products and services online. Accordingly, many banks and financial institutions have implemented internet banking to enhance efficiency, to reduce costs, and to improve services quality. The more banks and financial institutions utilize internet banking, the more essential it seems to recognize the factors influencing the customers' view of accepting and using these services. The present article has two key objectives: the first, presentation of a new model to study innovation acceptance; the second, the use of this model to investigate the factors affecting the internet banking acceptance in Guilan province. The results obtained from this model confirm major results of the past studies. The main advantage of the proposed model is that it is more comprehensive than the previous models. Therefore, it is appropriate in most cases. Based on the results of this study, Guilan province banks can develop marketing programs to encourage and persuade their customers to accept internet banking. On the whole, regarding the results found, in order to explain internet banking acceptance rate, the following suggestions are proposed.

Regarding the intensive effects of model variables, the measurement component, and the average points of each component, the trial ability of internet banking should first be provided partially, limited and on trial basis before deciding to use it in real sense. Concerning the current conditions, a temporary (one week) internet password for some low-risk bank affairs can be issued. Later, a permanent password can be issued if customer likes to have. The observation of other people while using internet banking can enhance its acceptance rate. Consequently, the second pace is to make some part of internet banking observable. Establishing free internet stations in big branches, shopping centers, airports and other crowded places helps customers have access to internet banking services and encourage them. This matter can increase the observation ability of internet banking usage. This act, in turn, raises the customers' confidence into the other people's use of this method, low-risk, easy, and useful internet banking, and finally boosts up its acceptance rate. The third factor that needs to be reinforced is image-making used in internet banking. Advertisement maneuvers on prestige and status of individuals who use internet can be effective on the acceptance of internet banking by young generation and future bank customers.

Since individual characteristic is the second variable in rank that affects internet banking acceptance rate, it should be attended to after innovation characteristics.
Considering this survey, the knowledge of using computer and internet should be fostered at first hand. Training how to use internet, and computer at university and work place can be a useful strategy. Holding training seminars to exhibit internet banking pages and banks website at schools can increase the internet banking acceptance rate among future customers of banks. Similarly, establishing a small ward inside banks for training people how to connect to internet, search sites and use the different services of internet banking can speed up the acceptance rate. As the base of internet banking increase, access to computer and internet should be paid attention to. Considering the existing conditions, it seems that by increasing the number of computers, expanding the space of sites at universities and work places along with providing free use of internet as well as providing more facilities in order for people to have more computers internet banking can be enhanced and the rate of its acceptance can be heightened. The third individual characteristic that should be reinforced is computer self-efficacy. Publishing brochures containing perfect information about internet banking with manual instructions, having a person or telephone number to contact while facing a problem or for troubleshooting all can add to the individuals' confidence in being able to use internet banking and can finally speed up its acceptance rate.

The market facilitating condition variable does not have direct impact on internet banking acceptance rate and can only affect it through individual and innovation characteristics. Regarding the average points of factors for market facilitating conditions, technological support should be worked up. To do so, improving the quality of internet connection, reducing the connection cuts, increasing to internet speed, making it public and lowering the price of high-speed internet accompanied with increasing web security can result in accessing technological support and promoting acceptance rate extraordinarily. Banks can have joint cooperation with internet service providers (ISPs) to provide quality internet with high speed. The second factor of market facilitating conditions requiring attention is accessibility to the government support. Some of the measures taken by the government to boost internet banking acceptance rate can be securing internet exchanges, punishing internet frauds, and encouraging people to use internet banking. The negative relationship between market facilitating conditions and individual characteristics should be considered in separated study.

Despite considerable results obtained in this study, it has some limitations that should not be overlooked. The first limitation refers to this fact that it surveys only one type of innovation that is internet banking. In order to increase the explanation power of the model, it is better to survey various innovative technologies in banking industry, for example by mobile banking, or technological innovations in different industries. The second limitation 
goes back the low number of internet banking users in Guilan province. This model can be tested with more users in other provinces.

\section{REFERENCES}

Al-somali SA, Gholami R, Clegg B (2008).an investigation the acceptance of online banking in Saudi Arabia.J. Technovation. 7: 112.

Atay E (2008).Macroeconomic Determinants of Radical Innovation and Internet Banking in Europe. Annals Universitatis Apulensis Series Oeconomica, 2: 1-6.

Chan S, Lu M (2004). Understanding internet adoption and use behavior: a Hong Kong Perspective. J. Global Inform. Manage., 12: 21-43.

Chau PYK, Lai VSK (2004). An empirical investigation of the determinants of user acceptance of internet banking. J. Organ. Comput. Elect. Commer., 13: 123-145.

Corrocher N (2006). Internet adoption in Italian banks: an empirical investigation. J. Res. Policy, 35: 533-544.

Eriksson K,Kerem K, Niksson D (2005).Costumer acceptance of internet banking in Estonia. Int. J. Bank Mark., 23: 200-216.
Eriksson K, Kerem K, Niksson D (2008). The adoption of commercial innovation in the former central and eastern European markets. Int. J. Bank Mark., 26: 282-304.

Gounaris S,Koritos CH (2008). Investigation the drivers of internet banking adoption decision: A comparison of three alternative framework. Int. J. Bank Mark., 26: 282-304.

Hernandez JMC, Mazzon JA (2007). Adoptioion of internet banking : proposition and implementation of an integrated methodology approach. Int. J. Bank Mark., 25: 72-88.

Mckechnie S, Winklhofer H, Ennew C (2007).Applying the technology acceptance model to the online retailing of financial services. Int. J. Retail Distrib. Manage., 34: 388-410.

Rogers EM, Shoemaker FF (1971). Communicatin of innovation: a cross-cultural approach. Free press, 2nd edition.

Suh B, Han I (2002). Effect of trust on customer acceptance of internet banking. Electron. Commer. Res. Appl., 1: 247-263.

Taylor S, Todd PA (1995).Understanding information technology: a test of competing models. Inform. Syst. Res. 6: 76-144.

www.ilcell.ir 